\title{
Monitoring Step Activity During Task-Oriented Circuit Training in High-Functioning Chronic Stroke Survivors: A Proof-of-Concept Feasibility Study
}

\author{
Sofia Straudi, MD, PhD ${ }^{1,2}$, Carlotta Martinuzzi, PT $^{1}$, Andrea Baroni, $\mathrm{PT}^{1}$, Maria Grazia Benedetti, $\mathrm{MD}^{3}$, \\ Calogero Foti, $\mathrm{MD}^{2}$, Amira Sabbagh Charabati, $\mathrm{PT}^{1}$, Claudia Pavarelli, $\mathrm{PT}^{1}$, Nino Basaglia, $\mathrm{MD}^{1}$

\begin{abstract}
${ }^{1}$ Department of Neuroscience and Rehabilitation, Ferrara University Hospital, Ferrara; ${ }^{2}$ Doctoral Program in Advanced Sciences and Technologies in Rehabilitation Medicine and Sports, University of Rome Tor Vergata, Rome;

${ }^{3}$ Physical Medicine and Rehabilitation Unit, Istituto Ortopedico Rizzoli, Bologna, Italy
\end{abstract}

\begin{abstract}
Objective To explore the amount of practice and progression during task-oriented circuit training (TOCT) in chronic stroke survivors; to test the use of pedometers and observation-based measures in detecting step activity; to verify the possible correlation between step activity and locomotor function improvements.

Methods Six community-dwelling chronic stroke survivors underwent 10 TOCT sessions (2 hours/each) over 2 weeks in which they were trained both on a treadmill and on six task-oriented workstations (W1-W6). During the sessions, they wore a piezoelectric pedometer and step activities were recorded. Outcome measures were as follows: \% of activities during which pedometers worked properly; pedometer-based measures (total step counts, treadmill steps, workstation steps- total and W2,W3,W5,W6); observation-based measures (number of repetitions in task W1 and W4); walking speed changes measured by the 10-m walking test (10MWT) and walking endurance changes (6-minute walking test) after TOCT.

Results During TOCT sessions $(n=57)$, activities were recorded through pedometer-based measures in 4 out of the 6 patients. The total amount of step activity was 5,980.05 $\pm 1,968.39$ steps $(54.29 \%$ in task-oriented workstations, $37.67 \%$ on treadmill, and $8.03 \%$ during breaks). Exercise progression was highlighted significantly by observational measures (W1, W4). A positive correlation was observed between increased gait speed and observational stair step repetitions progression (W1) $(\mathrm{r}=0.91, \mathrm{p}=0.01)$ or pedometer-based tandem exercise step progression (W3) $(\mathrm{r}=0.98$, $\mathrm{p}=0.01$ ).

Conclusion TOCT can be considered a high-intensity, progressive intervention to restore locomotor function in chronic stroke survivors. Pedometer-based measures might help in quantifying TOCT's volume of practice; however, further investigations are required.
\end{abstract}

Keywords Stroke, Rehabilitation, Gait

Received February 11, 2016; Accepted May 25, 2016

Corresponding author: Sofia Straudi

Department of Neuroscience and Rehabilitation, Ferrara University Hospital, Via della Fiera, Ferrara 44100, Italy. Tel: +39-3346262362, Fax: +3953228704, E-mail: s.straudi@ospfe.it

ORCID: Sofia Straudi (http://orcid.org/0000-0002-2061-9922); Carlotta Martinuzzi (http://orcid.org/0000-0001-6587-7098); Andrea Baroni (http:// orcid.org/0000-0002-8681-3090); Maria Grazia Benedetti (http://orcid.org/0000-0002-2623-8506); Calogero Foti (http://orcid.org/0000-0003-2246348X); Amira Sabbagh Charabati (http://orcid.org/0000-0003-2249-2838); Claudia Pavarelli (http://orcid.org/0000-0002-0997-8051); Nino Basaglia (http://orcid.org/0000-0001-6726-0315).

(a) This is an open-access article distributed under the terms of the Creative Commons Attribution Non-Commercial License (http://creativecommons.org/ licenses/by-nc/4.0) which permits unrestricted noncommercial use, distribution, and reproduction in any medium, provided the original work is properly cited. Copyright $\odot 2016$ by Korean Academy of Rehabilitation Medicine 


\section{INTRODUCTION}

Stroke is a leading cause of motor impairments and disability worldwide, and even in the chronic phase, survivors tend to be inactive which produces detrimental effects on mobility and quality of life [1]. Repetition, intensity and specificity of motor tasks are the essential key factors of learning-dependent neural plasticity and the amount of practice might influence functional recovery after stroke [2]. In clinical practice, it is now widely accepted that high-intensity and task-specific interventions, such as task-oriented circuit training (TOCT), are pivotal to achieve functional recovery after stroke $[3,4]$. TOCT is a relatively new concept in neurorehabilitation and it consists of progressive task-specific therapy provided in a group setting (class) [5]. TOCT is based on progressive task-specific exercises through workstations, in which subjects can be trained intensively on functional motor tasks. The duration of tasks, the frequency and progression have to be tailored according to the subjects' characteristics. Motor tasks should always be challenging and motivating to ensure neuroplastic changes and skills consolidation $[2,6]$; variety in practice and motor task salience are also essential. Participation of other patients in the same session might increase motivation, promote good competition and improve self-esteem; therefore, therapy adherence can be higher compared to that for an individual physiotherapy session. Another potential benefit of groups is that action observation might enhance motor learning and skills acquisition; indeed, when an action is observed, the brain generates activity that is similar to what occurs when the action is performed [7]. Finally, this new organization method has the potential to deliver more active therapy compared to the conventional one-to-one approach and to reduce staff costs [5].

It is well-known how a positive relationship develops between exercise intensity and outcomes [8]. Therefore, quantifying the volume of practice is an important topic in stroke rehabilitation research, and in a clinical trial, it is recommended to report repetitions of an exercise for a more accurate representation of the dose of the therapy received [8]. However, the definition of "dose" of practice is still an unsolved issue; so far, intensity has been described as "frequency of repetition of a specific movement" [9-11], or "amount of external work" [12] or "amount of time dedicated to practice" [13]. Measuring the external work or power is not feasible during TOCT; for this reason, we decided to focus our attention on the frequency of step repetitions, as it is directly related to the actual amount of practice. Previous studies on stroke survivors measured the duration of motor activity by video-taping or based on the therapist's report $[9,14]$; whereas few studies quantified the amount of practice during stroke rehabilitation $[4,10,15,16]$. Pedometers are wearable devices that provide useful information on physical activity [17] and they can also be used in stroke survivors [18] to detect daily step activity [1] or to assist in the community-based walking program [19]. The specific aims of this study were (1) to explore the volume of practice and progression during 120 minutes of TOCT and to assess their possible correlation with locomotor function improvements; (2) to test the use of pedometer- and observation-based measures in detecting step activity during TOCT.

\section{MATERIALS AND METHODS}

In a convenience sample, part of a pilot study where we assessed the effects of TOCT and transcranial direct current stimulation in patients with chronic stroke (NCT01883843), we quantified the amount of practice and exercise progression. Subjects were aged 18-75 years, with a diagnosis of first ischemic/hemorrhagic stroke $>6$ months, community-dwelling with a Functional Ambulation Classification (FAC) score $\geq 4$ that refers to patients who can walk independently on level ground but require help on stairs, slopes or uneven surfaces. Exclusion criteria were: (1) contraindications for tDCS; (2) medical conditions likely to interfere with the ability to complete the study safely; (3) impaired cognitive functioning (Mini Mental Status Examination score $<24$ ). All subjects underwent TOCT (10 sessions over 2 weeks); each session ( 2 hours) was divided between the treadmill (up to 30 minutes) and six task-oriented workstations (W1W6) in which subjects exercised for 5 minutes on each equipment (3 minutes of exercises and 2 minutes of rest). Workstations have been described in Table 1. During each session, subjects underwent 2 laps that took about 60 minutes ( 6 workstations $\times 5$ minutes $\times 2$ laps), with 10 minutes of rest after each lap. This was a progressive circuit and subjects while exercising received feedbacks (visual and auditory) from the physiotherapist. Rests 
Table 1. Methods of assessing step activity and repetitions during task-oriented circuit training

\begin{tabular}{|c|c|c|c|}
\hline \multicolumn{3}{|c|}{ Workstation description } & \multirow{2}{*}{$\begin{array}{l}\begin{array}{c}\text { How we counted } \\
\text { motor activity }\end{array} \\
\text { Up and down the step } \\
=1 \text { repetition }\end{array}$} \\
\hline $\begin{array}{l}\text { Observational- } \\
\text { based measures }\end{array}$ & Step (W1) & $\begin{array}{l}\text { The subject goes up and down a } 20-\mathrm{cm} \text { step } \\
\text { both with the left foot and the right foot. }\end{array}$ & \\
\hline & Goals (W4) & $\begin{array}{l}\text { The subject must touch a goal that is positioned } \\
\text { on a mirror in front of him/her with the tip of } \\
\text { the foot. If necessary, he/she can use a lateral } \\
\text { support. }\end{array}$ & $\begin{array}{l}\text { Touch of } 1 \text { goal } \\
=1 \text { repetition }\end{array}$ \\
\hline \multirow[t]{5}{*}{$\begin{array}{l}\text { Pedometer- } \\
\text { based measures }\end{array}$} & Slalom (W2) & $\begin{array}{l}\text { The subject kicks a ball walking through a slalom } \\
\text { exercise, formed by } 4 \text { cones that are } 1 \mathrm{~m} \text { away } \\
\text { from each other. }\end{array}$ & Steps/session \\
\hline & Tandem exercise (W3) & $\begin{array}{l}\text { The subject walks in tandem using a line as a guide. } \\
\text { If he/she is not able to put one foot in front of the } \\
\text { other, it is allowed to do a wider and longer step } \\
\text { as long as it is challenging. }\end{array}$ & Steps/session \\
\hline & Obstacles (W5) & $\begin{array}{l}\text { The subject must pass } 5 \text { obstacles, } 3 \text { of which are } \\
5 \mathrm{~cm} \text { high. }\end{array}$ & Steps/session \\
\hline & Long step (W6) & $\begin{array}{l}\text { The subject must walk by performing long steps } \\
\text { (at least } 40-50 \mathrm{~cm} \text { long) using some signs on the } \\
\text { floor as a guide. }\end{array}$ & Steps/session \\
\hline & Treadmill & $\begin{array}{l}\text { The subject should walk up to } 30 \text { minutes at a } \\
\text { speed between } 0.9 \text { and } 2.9 \mathrm{mph} \text {. The speed is } \\
\text { self-selected by the subject, who can also take a } \\
\text { break if he/she needs to rest. }\end{array}$ & Steps/session \\
\hline
\end{tabular}

were used to discuss regarding difficulties and to provide further feedbacks. One session included up to 3 patients [20].

Patients signed a written informed consent form approved by the Ethical Committee. During activities, patients wore a piezoelectric pedometer (Geonaute ONStep 100), which has been shown to be more suitable for subjects with low speed (i.e., stroke survivors) [17]. It was set according to the patients' anthropomorphic characteristics (height, weight) and was attached to the unaffected hip [18] at the beginning of each session and taken off at the end of training. We recorded step activity during each TOCT session (rest and breaks included); furthermore, workstation and treadmill step activities were manually recorded in a precompiled log; in two workstations, stair step (W1) and goal (W4), we hypothesized that the use of the pedometer was not appropriate to detect repetition; therefore, the number of task repetitions observed was reported (observation-based measures). Data were collected by two physiotherapists (CM and $\mathrm{AB}$ ).

The $10-\mathrm{m}$ walking test (10MWT) and the 6 -minute walking test (6MWT) were performed pre- and post- training to detect any changes in locomotor function. Moreover, walking speed was used to classify the sample into the walking behaviour (household ambulators, $<0.4$ $\mathrm{m} / \mathrm{s}$; limited community ambulators, $0.4-0.8 \mathrm{~m} / \mathrm{s}$; and community ambulators, $>0.8 \mathrm{~m} / \mathrm{s}$ ) [21]. Also, the use of walking aids or the presence of major kinematic deviations was reported. The two physiotherapists assessed the subjects' gait by observing their walk and categorizing it as 'normal' or 'hemiparetic.' If they failed to agree, they discussed it until an agreement was reached.

\section{Statistical analysis}

Descriptive statistics as means and standard deviations were used to analyse workstation and treadmill step activity. We calculated the percentages of activities performed during the sessions and also the percentages of activities where it was possible to record steps with pedometers to test the feasibility of pedometer-based measures. We registered the total steps (break and rests included), total steps during each workstation activity and total steps on the treadmill to test the ability of measures to determine exercise volume for each session. We analysed 
the differences among sessions using the ANOVA repeated measures analysis, and Tukey's post-hoc pairwise comparison to underline exercise progression. Moreover, the effect size (Cohen's d) was calculated for each variable considering the progression between sessions 1 and 10. Pearson coefficient correlation was used to test any possible association between exercise progression and clinical gains. All data available were included in the final analysis; missing data were handled with the last observation carried forward approach, and conditions when the pedometers did not record properly were excluded. Significance levels were set at $\mathrm{p}<0.05$. STATA/IC ver. 13 was used for statistical analysis.

\section{RESULTS}

We tested the use of pedometers in six communitydwelling chronic stroke survivors ( 3 men, 3 women; mean age, $58.67 \pm 14.18$ years, $6.2 \pm 6.1$ years after stroke). Sample characteristics are summarized in Table 2.

We analyzed data recorded over 57 TOCT sessions performed by six community-dwelling chronic stroke survivors over 2 weeks ( 3 subjects missed 1 session for personal issues). According to their speed-based walking performance, 2 subjects ( $33 \%$ ) were classified as limited community ambulators $(<0.8 \mathrm{~m} / \mathrm{s})$, whereas 4 subjects (66\%) were classified as full community ambulators (gait speed $>0.8 \mathrm{~m} / \mathrm{s}$ ) [21]. None of the subjects needed walk-

Table 2. Characteristics of study subjects $(n=6)$

\begin{tabular}{lc}
\hline & Value \\
\hline Age (yr) & $58.7 \pm 14.18$ \\
Sex (male:female) & $3: 3$ \\
Stroke etiology (ischemic:hemorrhagic) & $4: 2$ \\
Stroke onset (yr) & $6.2 \pm 6.1$ \\
Side hemiparesis (left:right) & $1: 5$ \\
FAC & $4.5 \pm 0.55$ \\
Stroke type & \\
\hline Subcortical stroke & 3 \\
\hline Cortical stroke & 2 \\
\hline ND & 1 \\
\hline
\end{tabular}

Values are presented as mean \pm standard deviation or number.

FAC, Functional Ambulation Classification; ND, not defined. ing aids ( $0 \%)$ and three out of the 6 subjects had major hemiparetic gait abnormalities (50\%). No injuries, falls or fatigability were recorded throughout the sessions. Pedometers were easily worn under the PT's supervision and they did not interfere with activities or were not displaced during exercises.

During the TOCT sessions, $94.1 \% \pm 5.9 \%$ of the pre-determined motor activities were performed by our sample and the subjects walked on a treadmill for $24.37 \pm 7.91$ minutes (min 4-max 30) at 0.9-1.8 mph. Pedometerbased measures were obtained in $66.5 \% \pm 51.4 \%$ of these activities. Specifically, in 4 out of the 6 subjects, we recorded $>98 \%$ of all episodes, whereas in 2 subjects, the pedometer failed to work properly. They were characterized by lower gait speed $(0.79 \mathrm{~m} / \mathrm{s}$ and $0.71 \mathrm{~m} / \mathrm{s})$ and major hemiparetic gait abnormalities. Considering how these variables might reflect malfunctioning of the pedometers [18], we correlated these data with baseline gait speed $(\mathrm{r}=0.88, \mathrm{p}<0.01)$ and gait abnormalities $(\mathrm{r}=0.70$, $\mathrm{p}=0.11)$.

The total amount of step activity during each 120-minute session was $5,980.05 \pm 1,968.39$ steps (breaks and rests included), with an overall mean cadence of 49 steps $/ \mathrm{min}$; this was distributed as follows: $54.29 \%$ in 60 minutes of task-oriented workstations ( 54 steps/min), $37.67 \%$ during the treadmill exercise (93 steps/min), and $8.03 \%$ during breaks (30 minutes). Regarding progression across sessions, the patients were able to increase the number of repetitions significantly for the stair step $(\mathrm{F}=4.35$, $\mathrm{p}<0.001)$ and goals in workstation $(\mathrm{F}=3.67, \mathrm{p}<0.01)$. However, a medium to large effect size (Cohen's d) between the first and last session in each workstation was reported, as shown in Table 3. A power analysis was conducted, and considering the lower effect size $(\mathrm{d}=0.56)$ registered in slalom workstation (W2), $90 \%$ power and alpha of $5 \%$, it will be necessary to enroll 29 subjects in a future study to detect any significant progression in each workstation.

Pre-training walking speed was $1.02 \pm 0.23 \mathrm{~m} / \mathrm{s}$, which increased to $1.14 \pm 0.24 \mathrm{~m} / \mathrm{s}$ after treatment $(\mathrm{p}<0.05)$, whereas walking endurance was $247.23 \pm 20.68 \mathrm{~m}$ and it increased to $291.1 \pm 24.58 \mathrm{~m}$. We found a positive correlation between increased gait speed and observation-based stair step repetitions progression (W1) $(\mathrm{r}=0.91, \mathrm{p}=0.01)$ or pedometer-based tandem exercise step progression (W3) $(\mathrm{r}=0.98, \mathrm{p}=0.01)$, as reported in Fig. 1 .

Moreover, correlations close to achieving significance 


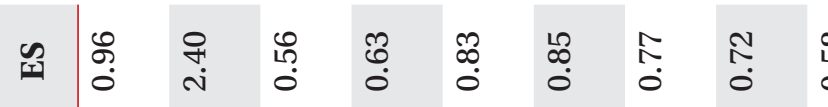

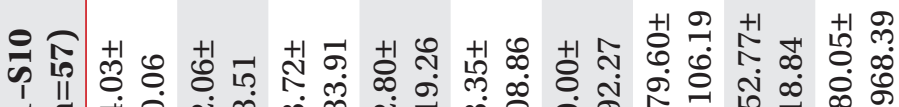

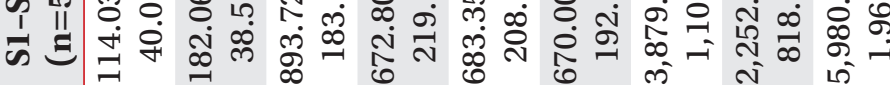

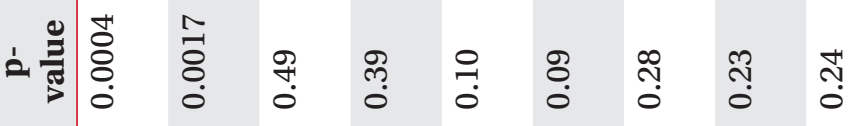

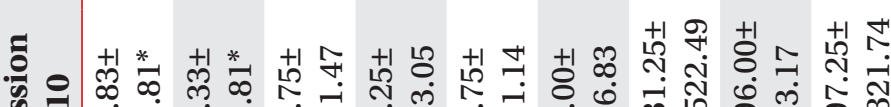

की

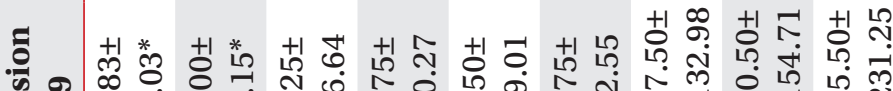

ํ.

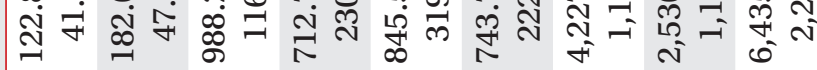

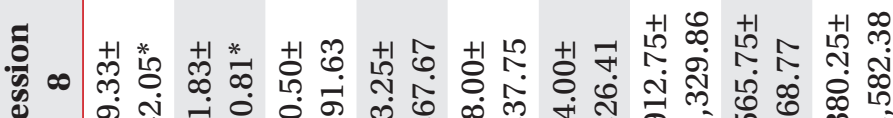

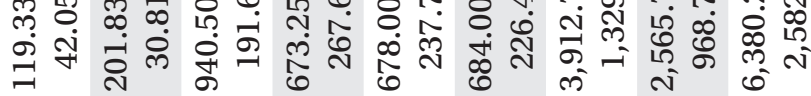

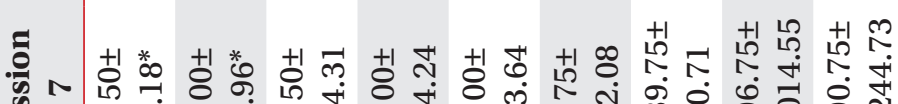

फ

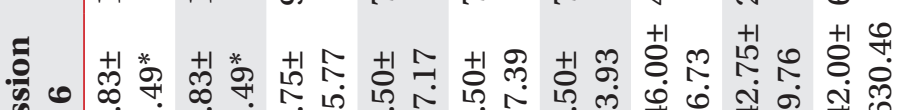

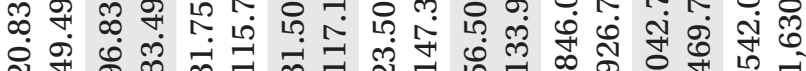

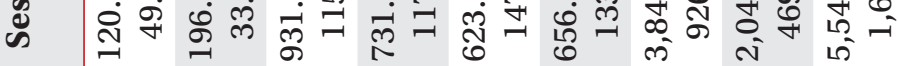

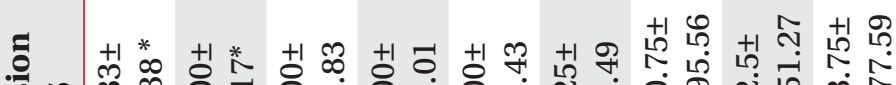

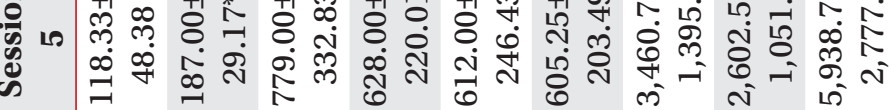

贰

क छ

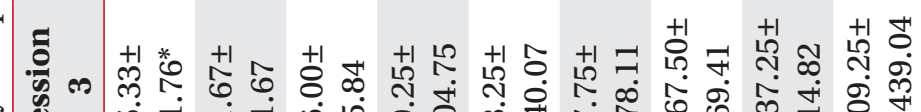

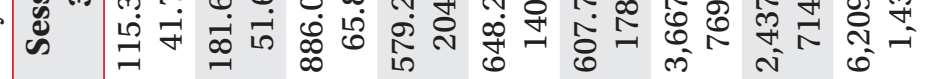

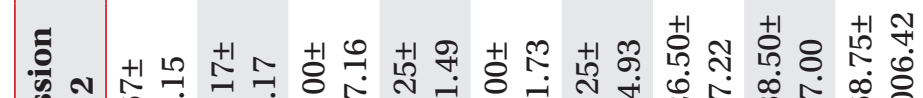

管

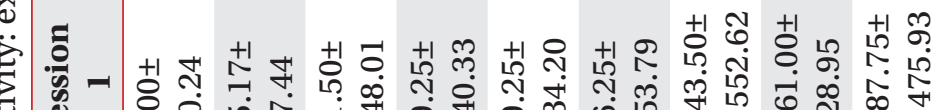

की

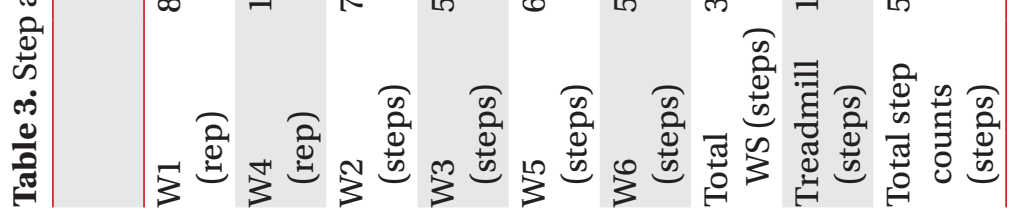

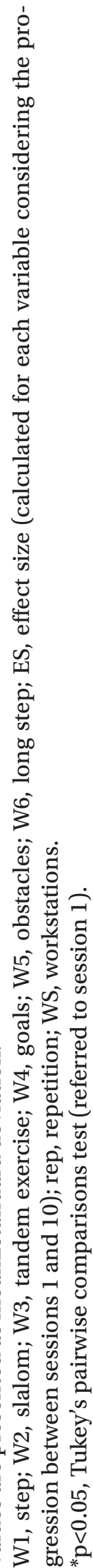



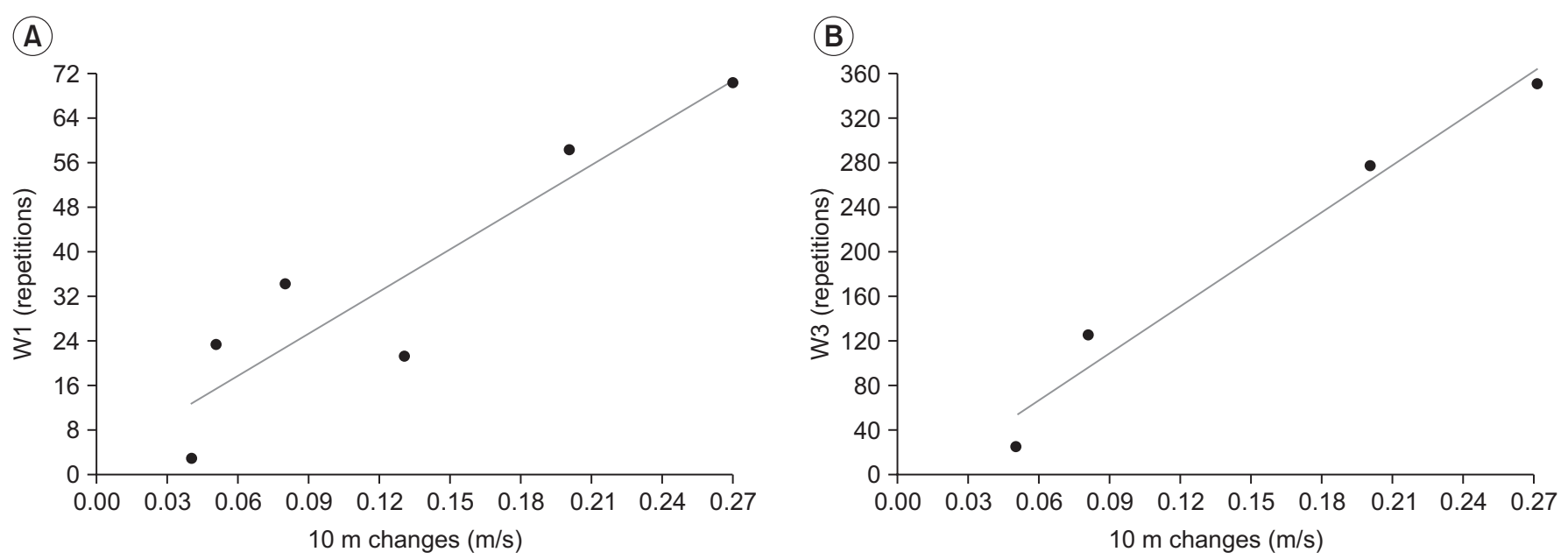

Fig. 1. Correlation between clinical outcome (gait speed) and exercise progression (S1-S10). (A) observation-based stair step repetitions workstation (W1) $(\mathrm{r}=0.91, \mathrm{p}=0.01)$. (B) Pedometer-based tandem workstation (W3) ( $\mathrm{r}=0.98$, $\mathrm{p}=0.01$ ).

were found with total step counts progression ( $\mathrm{r}=0.88$, $\mathrm{p}=0.11)$, pedometer-based obstacles step progression $(\mathrm{r}=0.81, \mathrm{p}=0.18)$ and total workstation step progression $(\mathrm{r}=0.83, \mathrm{p}=0.06)$. We found a correlation close to achieving significance between walking endurance and total step counts progression $(\mathrm{r}=0.85, \mathrm{p}=0.14)$.

\section{DISCUSSION}

In this proof-of-concept feasibility study, we explored the use of pedometer-based and observational-based measures to count step activity and progression during TOCT sessions in community-dwelling chronic stroke survivors. Evidence from animal models showed how induction of neuroplasticity requires sufficient training intensity. In addition to repetition, intensity of training can also affect induction of cortical reorganization processes. Indeed, it has been shown how animals trained on a skilled reaching task to perform 400 reaches per day had an increase in synapse number within motor cortex [22], whereas animals trained to reach 60 times per day did not have such increases [23]. In clinical practice, it is well-known how a positive relationship develops between intensity and outcome. Furthermore, it is recommended to report repetitions of an exercise for a more accurate representation of the dose of the therapy received [8]. In rehabilitation medicine, the definition of "dose" of practice remains one of the unsolved issues. In this paper, we considered intensity as "frequency of repetition of a task" [4,9-11]. However, from the exercise physiology viewpoint, the term "intensity" refers to the amount of external work produced during a motor task. Unfortunately, measuring the energy spent to perform certain motor tasks is not always feasible due to the lack of equipment required to measure the external power produced. For this reason, in rehabilitation medicine, the number of repetitions of a motor task [4,9-11] or the time spent on practice [24] is commonly used to reflect the dose of practice applied, even if it is considered to be a less optimal estimate.

In our sample, the pedometer was feasible only in subjects who were classified as full community ambulators (gait speed $>0.8 \mathrm{~m} / \mathrm{s}$ ). Previous studies reported about low accuracy of pedometers in detecting steps in subjects with low speed $[17,18]$, although this did not seem to be the only factor (i.e., the use of walking aids and the presence of kinematic gait deviations) [18]. Our findings suggested that pedometers were suitable in subjects with gait speed $>0.8 \mathrm{~m} / \mathrm{s}$, as previously reported by Fulk et al. [25], who tested the accuracy of activity monitors and pedometers in a sample of community ambulators with chronic stroke who walked at $0.83 \mathrm{~m} / \mathrm{s}$. Below this threshold our pedometers did not record step counts, which are higher than those detected by Carroll et al. [18] (about $0.5 \mathrm{~m} / \mathrm{s}$ ); we can hypothesize that this discrepancy is because of the concomitant presence of kinematic gait deviations in our subjects.

During a TOCT session, our sample maintained an 
overall cadence of 49 steps/min, which reflects a 'high intensity' intervention for stroke survivors that can contribute to cardiovascular health [1]. This intervention combines both locomotor activity on a treadmill and in different contexts where subjects performed numerous repetitions of a single task (long steps, slaloms, tandem, passing small obstacles, stair steps and achieving goals) that seems to be essential for neuroplasticity and motor recovery [26]. Clearly, these activities require slower speeds and increased attention compared to walking on a treadmill, which explains the different aerobic intensities (54 steps/min vs. 93 steps/min).

Considering how repetitions, progression and specificity are the key factors in motor learning and rehabilitation gains [2], we counted the number of repetitions during the step (W1) and achieving goals (W4) task; otherwise, we considered pedometer step counts over the entire session, divided them into treadmill and workstation activities. The amount of stair steps achieved during TOCT was 3 - to 6 -fold higher compared to that in other studies $[4,10]$ which assessed the amount of stair task repetitions during conventional stroke physiotherapy sessions [10] or a task-oriented session in acute stroke survivors [4]. Considering the whole step activity during TOCT (2 hours), subjects performed approximately 1,500 steps more than those during 1 hour of intensive locomotor training, which is still 4-fold more intensive than 1 hour of conventional physiotherapy [15]. In conclusion, 2 hours of TOCT provides approximately 4,500 steps more than those during 1 hour of conventional physiotherapy $[10,15]$; the volume of practice was similar to that reported by Holleran et al. [16] who, in chronic stroke survivors, delivered 2,967 steps during 1 hour of stepping activities (treadmill, overground and stair climbing), even though their target population had a significantly lower locomotor function $(0.56 \mathrm{~m} / \mathrm{s}$ vs. $1.02 \mathrm{~m} / \mathrm{s})$. Observation-based measures rather than pedometer-based measures were accurate enough to detect progression among sessions; nevertheless, even pedometer-based measures, collected during workstation and treadmill activities, revealed a medium to large effect size (0.56-0.85). As reported previously, pedometers are a valid device to measure step activity in ambulatory stroke survivors; however, they tend to undercount steps during other activities of short duration [27]. Furthermore, other activity monitor devices may be more accurate than pedometers to detect walking activi- ties in chronic stroke survivors [25].

After TOCT, we found an overall improvement in walking speed, $0.12 \mathrm{~m} / \mathrm{s}$ which is above the minimally clinical important difference (MCID) stated for the 10MWT [28]. This finding reflects the positive effects of a task-oriented intervention in community ambulators who are chronic stroke survivors. Furthermore, when we looked at a possible dose-response relationship among the variable selected (step activities) and locomotor function improvements, we found a positive correlation between stair-step progression, measured by observation, tandem progression, measured by the pedometer and speed gains. This corroborates the hypothesis that a higher volume of training (i.e., stair step repetitions) may enhance gait speed in chronic stroke survivors [24]. In future larger studies, it would be worthwhile to test if a low-cost pedometer, as used in this proof-of-concept study, is accurate enough to detect significant changes in step activity progression with a solid correlation with functional outcome. This might provide a great contribution to the field of the dose-response relationship in stroke rehabilitation medicine research. Moreover, future studies should aim at determining which components (treadmill, different workstations) lead to this functional gain.

This proof-of-concept study has several limitations. Firstly, the small number of observations and the low variability in gait speed between subjects reduce the generalization of the results. Indeed, our sample is quite high-functioning, with a pre-training walking speed of $1.02 \mathrm{~m} / \mathrm{s}$, which is quite high compared to that in many patients seen in a rehabilitation setting who usually ambulate at a much slower pace. In future studies, it would be worth considering patients with slower speeds, even if in this preliminary report, our pedometers failed to record step activity in 2 subjects with gait speed $<0.8 \mathrm{~m} / \mathrm{s}$. Secondly, the accuracy of the pedometer device used in this paper has not been tested previously (i.e., compared to observation or accelerometer), even if similar devices have been tested [25,27]. Thirdly, the mere observation of kinematic gait deviations (yes/no) might not represent the most effective way to detect gait abnormalities; in future researches, the additional use of instrumental gait analysis might help determine the patients who are better suited to use pedometers during a rehabilitative intervention.

In conclusion, TOCT can be considered a high-intensi- 
ty, progressive intervention to restore locomotor function in chronic stroke survivors. Our report suggested a novel use of pedometers, not only for monitoring step activity in real-life conditions but also during rehabilitation, in high-functioning stroke survivors. In our report, exercise dose was tightly controlled and this model can be replicated in future clinical trials including a new metric of intensity, in addition to duration of therapy.

\section{CONFLICT OF INTEREST}

No potential conflict of interest relevant to this article was reported.

\section{ACKNOWLEDGMENTS}

The authors (CM, AB, ASC, and $\mathrm{CP}$ ) were supported by Emilia Romagna region (Grant No. 1786/2012).

\section{REFERENCES}

1. Michael K, Macko RF. Ambulatory activity intensity profiles, fitness, and fatigue in chronic stroke. Top Stroke Rehabil 2007;14:5-12.

2. Kleim JA, Jones TA. Principles of experience-dependent neural plasticity: implications for rehabilitation after brain damage. J Speech Lang Hear Res 2008;51:S225-39.

3. Kwakkel G, van Peppen R, Wagenaar RC, Wood Dauphinee S, Richards C, Ashburn A, et al. Effects of augmented exercise therapy time after stroke: a metaanalysis. Stroke 2004;35:2529-39.

4. Rose D, Paris T, Crews E, Wu SS, Sun A, Behrman AL, et al. Feasibility and effectiveness of circuit training in acute stroke rehabilitation. Neurorehabil Neural Repair 2011;25:140-8.

5. English CK, Hillier SL, Stiller KR, Warden-Flood A. Circuit class therapy versus individual physiotherapy sessions during inpatient stroke rehabilitation: a controlled trial. Arch Phys Med Rehabil 2007;88:955-63.

6. Adkins DL, Boychuk J, Remple MS, Kleim JA. Motor training induces experience-specific patterns of plasticity across motor cortex and spinal cord. J Appl Physiol (1985) 2006;101:1776-82.

7. Fadiga L, Fogassi L, Pavesi G, Rizzolatti G. Motor facilitation during action observation: a magnetic stimula- tion study. J Neurophysiol 1995;73:2608-11.

8. Lohse KR, Lang CE, Boyd LA. Is more better? Using metadata to explore dose-response relationships in stroke rehabilitation. Stroke 2014;45:2053-8.

9. Nugent JA, Schurr KA, Adams RD. A dose-response relationship between amount of weight-bearing exercise and walking outcome following cerebrovascular accident. Arch Phys Med Rehabil 1994;75:399-402.

10. Potempa K, Lopez M, Braun LT, Szidon JP, Fogg L, Tincknell T. Physiological outcomes of aerobic exercise training in hemiparetic stroke patients. Stroke 1995;26:101-5.

11. Kwakkel G, Wagenaar RC, Koelman TW, Lankhorst GJ, Koetsier JC. Effects of intensity of rehabilitation after stroke: a research synthesis. Stroke 1997;28:1550-6.

12. English C, Hillier S, Kaur G, Hundertmark L. People with stroke spend more time in active task practice, but similar time in walking practice, when physiotherapy rehabilitation is provided in circuit classes compared to individual therapy sessions: an observational study. J Physiother 2014;60:50-4.

13. West T, Bernhardt J. Physical activity in hospitalised stroke patients. Stroke Res Treat 2012;2012:813765.

14. Lang CE, Macdonald JR, Reisman DS, Boyd L, Jacobson Kimberley T, Schindler-Ivens SM, et al. Observation of amounts of movement practice provided during stroke rehabilitation. Arch Phys Med Rehabil 2009;90:1692-8.

15. Moore JL, Roth EJ, Killian C, Hornby TG. Locomotor training improves daily stepping activity and gait efficiency in individuals poststroke who have reached a "plateau" in recovery. Stroke 2010;41:129-35.

16. Holleran CL, Straube DD, Kinnaird CR, Leddy AL, Hornby TG. Feasibility and potential efficacy of highintensity stepping training in variable contexts in subacute and chronic stroke. Neurorehabil Neural Repair 2014;28:643-51.

17. Melanson EL, Knoll JR, Bell ML, Donahoo WT, Hill JO, Nysse LJ, et al. Commercially available pedometers: considerations for accurate step counting. Prev Med 2004;39:361-8.

18. Carroll SL, Greig CA, Lewis SJ, McMurdo ME, Sniehotta FF, Johnston M, et al. The use of pedometers in stroke survivors: are they feasible and how well do they detect steps? Arch Phys Med Rehabil 2012;93:466-70.

19. Sullivan JE, Espe LE, Kelly AM, Veilbig LE, Kwasny 
MJ. Feasibility and outcomes of a community-based, pedometer-monitored walking program in chronic stroke: a pilot study. Top Stroke Rehabil 2014;21:101-10.

20. Straudi S, Martinuzzi C, Pavarelli C, Sabbagh Charabati A, Benedetti MG, Foti C, et al. A task-oriented circuit training in multiple sclerosis: a feasibility study. BMC Neurol 2014;14:124.

21. Bowden MG, Balasubramanian CK, Behrman AL, Kautz SA. Validation of a speed-based classification system using quantitative measures of walking performance poststroke. Neurorehabil Neural Repair 2008;22:672-5.

22. Kleim JA, Barbay S, Cooper NR, Hogg TM, Reidel CN, Remple MS, et al. Motor learning-dependent synaptogenesis is localized to functionally reorganized motor cortex. Neurobiol Learn Mem 2002;77:63-77.

23. Luke LM, Allred RP, Jones TA. Unilateral ischemic sensorimotor cortical damage induces contralesional synaptogenesis and enhances skilled reaching with the ipsilateral forelimb in adult male rats. Synapse 2004;54:187-99.
24. Cooke EV, Mares K, Clark A, Tallis RC, Pomeroy VM. The effects of increased dose of exercise-based therapies to enhance motor recovery after stroke: a systematic review and meta-analysis. BMC Med 2010;8:60.

25. Fulk GD, Combs SA, Danks KA, Nirider CD, Raja B, Reisman DS. Accuracy of 2 activity monitors in detecting steps in people with stroke and traumatic brain injury. Phys Ther 2014;94:222-9.

26. Van den Brand R, Heutschi J, Barraud Q, DiGiovanna J, Bartholdi K, Huerlimann M, et al. Restoring voluntary control of locomotion after paralyzing spinal cord injury. Science 2012;336:1182-5.

27. Vanroy C, Vissers D, Cras P, Beyne S, Feys H, Vanlandewijck $\mathrm{Y}$, et al. Physical activity monitoring in stroke: SenseWear Pro2 activity accelerometer versus Yamax Digi-Walker SW-200 pedometer. Disabil Rehabil 2014;36:1695-703.

28. Perera S, Mody SH, Woodman RC, Studenski SA. Meaningful change and responsiveness in common physical performance measures in older adults. J Am Geriatr Soc 2006;54:743-9. 